\title{
ANALISIS FAKTOR KRITIS KEBERHASILAN PADA IMPLEMENTASI E-PROCUREMENT
}

\author{
Eli Suryani \\ Information Systems Department, School of Information Systems, Binus University \\ Jl. K.H. Syahdan No. 9, Palmerah, Jakarta Barat 11480 \\ dc_eli@binus.edu
}

\begin{abstract}
The purpose of this study is to analyze the Critical Success Factor of e-procurement implementation, that is able to show the influence factors of successful implementation of e-procurement in companies. This study uses benchmarking method to examine the non-random selected samples from some companies which are advanced in implementing e-procurement including the contextual analysis of issues related to similar situations. From the findings then performed the identification and benchmarking study, mapping towards the successful practice at the companies. Eventually it is concluded that there is no best standard for e-procurement as the factors most affecting successful implementation are non-technical, of which this understanding will be the first step to systematically analyze the supporting factors in implementing e-procurement successfully. Therefore, e-procurement does not only improve the operational performance of the company in efficiency improvement of enterprise's supply chain management process but also provide added value for the company.
\end{abstract}

Keywords: e-procurement, supply chain management, benchmarking, critical success factor

\begin{abstract}
ABSTRAK
Tujuan penelitian ini adalah menganalisis Critical Success Factor implementasi e-procurement, sehingga dapat mengetahui pengaruh kesuksesan implementasi e-procurement pada perusahaan. Penelitian ini menggunakan metode benchmarking dengan meneliti studi kasus dari sampel yang dipilih non-random (purpose sampling) pada perusahaan yang memiliki praktek unggul dalam mengimplementasikan e-procurement yang meliputi analisis kontekstual terhadap hal yang berkaitan dengan situasi serupa dalam beberapa perusahaan. Dari temuan kemudian dilakukan identifikasi dan studi pembandingan, serta pemetaan terhadap praktek sukses perusahaan. Dapat disimpulkan bahwa tidak ada standar terbaik untuk e-procurement dan faktor yang mempengaruhi keberhasilan implementasi e-procurement yang terbesar adalah faktor non-teknis, dimana pemahamannya akan menjadi langkah pertama analisis sistematis terhadap faktor yang dapat memandu perusahaan dalam implementasi e-procurement yang berhasil. Oleh karena itu, e-procurement tidak hanya secara signifikan dapat meningkatkan kinerja operasional perusahaan dalam efisiensi manajemen rantai pasokan tapi juga memberikan nilai tambah bagi perusahaan.
\end{abstract}

Kata kunci: e-procurement, manajemen rantai pasokan, benchmarking, critical success factor. 


\section{PENDAHULUAN}

Perubahan yang cepat dan dinamis di lingkungan bisnis membuat perusahaan mencoba menemukan bisnis model baru dan melakukan pendekatan strategis. Dengan tekanan ini, perusahaan perlu menemukan cara untuk meningkatkan manajemen rantai pasokan (supply chain) yang strategis dalam rangka mengurangi biaya, meningkatkan efisiensi, dan mengurangi waktu penyediaan barang sebagai hal utama suatu bisnis (Puschmann \& Alt, 2005).

Bagian utama dari rantai pasokan dalam bagian pengadaan, adalah pembelian barang dan jasa dalam organisasi (Puschmann \& Alt, 2005) yang merupakan salah satu item biaya terbesar dalam struktur biaya perusahaan (Angeles \& Nath, 2005), sehingga proses pengadaan menjadi salah satu pusat sorotan pada perusahaan (Tari, 2008). Tidak heran, teknologi berbasis internet pada abad 21 memunculkan e-procurement yang bertujuan membantu manajemen rantai pasokan secara profesional dalam menghubungkan komponen yang diperlukan, untuk meningkatkan kecepatan transfer informasi dan mengurangi proses yang tidak memberikan nilai tambah (Pearcy et al, 2008), yang diperlukan untuk mencapai efisiensi manajemen rantai pasokan sebagai keunggulan kompetitif operasi perusahaan (Angeles \& Nath, 2005) dengan fokus pada efisiensi biaya proses dan biaya pengadaan.

Memahami faktor-faktor positif yang mempengaruhi adopsi teknologi e-procurement akan membantu organisasi mengembangkan strategi saat melakukan implementasi (Dooley \& Sharon, 2006). Best practice pada implementasi e-procurement telah menunjukkan keberhasilan yang signifikan dalam pengurangan biaya dan efisiensi proses. Namun, perusahaan atau institusi ini bergerak maju untuk mendapatkan peluang meningkatkan nilai tambah lainnya dari implementasi $e$ procurement.

\section{METODE}

Metode yang digunakan dalam penelitian ini meliputi beberapa tahap, yaitu: persiapan, menentukan kriteria objek perbandingan, seleksi, sintesis data, dan desain model.

\section{Persiapan}

Tahap persiapan dilakukan dengan mencari objek perbandingan dari perusahaan yang dapat dijadikan contoh terbaik dalam penerapan e-procurement, yang memiliki kompetensi dan standar sesuai dengan kriteria yang akan didefinisikan.

\section{Menentukan Kriteria Objek Perbandingan}

Kriteria objek perbandingan (benchmarking) perusahaan dikaji secara kualitatif dan kuantitatif. Kualitatif benchmarking membutuhkan definisi objek perbandingan yang jelas untuk memastikan dilakukan pengukuran perbandingan keberhasilan yang baik (Camp, 1989). Benchmarking yang dilakukan berfokus pada identifikasi kesuksesan berbagai industri dalam mengimplememtasikan e-procurement, sehingga dihasilkan konsep, metode dan model yang telah teruji dalam lebih dari satu perusahaan yang membawa perusahaan ke dalam kondisi yang unggul. Benchmarking dilakukan dengan dua pendekatan berdasarkan: (1) tujuan pembandingan yang difokuskan untuk membandingkan tingkat efisiensi sebagai dasar kunci indikator kinerja dalam menentukan level perusahaan. Tujuan perbandingan kualitatif (Tabel 1) adalah untuk menghasilkan konsep yang direferensikan, metode dan model untuk rancangan dan transfer keberhasilan dari suatu perusahaan; (2) Horison dari pembandingan (horizon of comparison) - benchmarking disesuaikan 
dengan fokus organisasi. Internal benchmarking membandingkan best practice secara kuantitatif, dengan key performance indicator. Secara eksternal, melakukan perbandingan kompetitif posisi perusahaan dengan industri sejenis (Boutellier et al., 1999).

\section{Seleksi}

Pada tahap ini ditentukan industri alternatif yang menjadi bahan kajian sebagai berikut (Puschmann \& Alt, 2005): (1) Babcock Borsig AG, berpusat di Oberhausen, Jerman. Sebuah group industry teknologi yang beroperasi di bidang power engineering dan shipbuilding. Dengan struktur organisasi yang terdesentralisasi, Babcock menjalankan proses pembelian secara desentralisasi. Babcock menggunakan e-procurement berbasiskan lotus notes yang menangani 90\% pengadaan tidak langsung dalam perusahaan; (2) Bayer AG, berpusat pada Leverkusen, Jerman. Perusahaan ini berkompeten pada produk kimia dan farmasi. Mereka mengimplementasikan SAP Business-toBusiness sebagai sistem e-procurement-nya menggunakan model bundling project dalam secara global untuk mendapatkan sinergi baik secara vertikal dan horizontal dalam pengadaan; (3) Cisco System, Inc, merupakan manufaktur dari peralatan dan layanan terkait jaringan, berpusat di San Jose, USA. Cisco mengatur pengadaaannya sesuai dengan keberagaman komoditas yang perusahaan miliki. Sejak 1996 Cisco System mengimplementasikan Ariba Operating Resource Management System (ORMS) dengan transaksi pembelian sekitar 60\% dari semua barang (indirect goods) dan jasa layanan dari 17 pemasok; (4) SAP, AG, berpusat di Walldorf, Jerman.

Perusahaan ini merupakan pemasok produk ERP terbesar di dunia. Tahun 1999 mereka memulai divisi pembelian yang bertanggungjawab dalam meakukan koordinasi transaksi internasional. SAP, AG menggunakan solusi SAP Business-to-Business dengan transaksi sekitar 16.000 item barang untuk servis dan IT; (5) Xerox Ltd, berpusat di London, UK. Perusahaan ini adalah manufaktur mesin fotocopy, printer, scanner, software dan servis. Pada tahun 1999 merka memulai proyek pengadaan yang berfokus pada reorganisasi dari 16 negara yang mengadakan pengadaaan secara independen, melalui sentralisasi yang membawahi area tingkat pan-european. Xerox juga memiliki kekuatan fokus pada pengadaan servis yang menjadi porsi terbesar dari total pengadaannya; (6) City of Helsinki, perusahaan sektor umum milik group metropolis ternama di Eropa yang memiliki 30 divisi dengan bidang yang berbeda (kesehatan, pendidikan, dll). Setiap tahunnya mereka terhubung dengan 10.000 pemasok. Sistem barunya telah meliputi 100 katalog dengan 7000 pengguna sistem yang melakukan pembelian produk dan terdiri dari 50 orang pembelian. Setiap tahunnya sistem e-procurementnya melakukan ratusan ribu transaksi.

\section{Sintesis Data}

Tahap keempat ini melakukan analisis bagaimana proses bisnis bagian pengadaan dari masing-masing perusahaan. Selain itu menganalisis beberapa faktor yang menjadi highlight dalam implementasi e-procurement pada perusahaan besar, yaitu: penyelerasan pada proses pembelian, perubahan pada pengaturan/organisasi proses pengadaan, persiapan penawaran katalog atas harga terbaik untuk produk berkualitas, penjangkauan pemasok, serta integrasi sistem e-procurement dan sistem back-end/ operasional perusahaan.

Selain membenahi proses pengadaan, manajemen katalog adalah salah satu kunci faktor keberhasilan yang penting (Smeltzer, 2001; Poole and Durieux, 1999). Perusahaan melakukan proses indentifikasi komoditas yang akan menentukan strategi pengadaan (Tabel 2). 
Tabel 1

Perbandingan Kualitatif Praktek Unggul Perusahaan

\begin{tabular}{|c|c|c|c|c|c|c|c|c|}
\hline Perusahaan & & $\begin{array}{c}\text { Persiapan } \\
\text { Project }\end{array}$ & & Organisasi & & $\begin{array}{c}\text { Manajemen } \\
\text { Katalog }\end{array}$ & $\begin{array}{c}\text { Proses Rantai } \\
\text { Pasokan } \\
\text { dan Sistem } \\
\text { Arsitektur }\end{array}$ & $\begin{array}{c}\text { Efisiensi } \\
\text { Operasional }\end{array}$ \\
\hline Babcock Borsig & (1) & $\begin{array}{l}\text { Sentralisasi } \\
\text { proses } \\
\text { permintaan } \\
\text { dan } \\
\text { pembelian } \\
\text { Strategi } \\
\text { pembelian } \\
\text { 'bundling' } \\
\text { dengan } \\
\text { melakukan } \\
\text { transaksi } \\
\text { pembelian } \\
\text { volume besar }\end{array}$ & (1) & $\begin{array}{l}\text { Mengurangi } \\
\text { struktur organisasi } \\
\text { yang panjang } \\
\text { Desentralisasi } \\
\text { operasional bagian } \\
\text { pengadaaan }\end{array}$ & (1) & $\begin{array}{l}\text { Mengindentifikasi } \\
\text { komoditas untuk } \\
\text { menentukan } \\
\text { strategi proses } \\
\text { pengadaan yang } \\
\text { akan digunakan } \\
\text { Transaksi besar } \\
\text { berfokus pada } \\
\text { indirect goods }\end{array}$ & & \multirow{2}{*}{$\begin{array}{l}\text { (1) Melakukan } \\
\text { pengukuran } \\
\text { terhadap } \\
\text { peningkatan } \\
\text { efisiensi dari } \\
\text { waktu ke waktu } \\
\text { dalam hal : } \\
\text { proses, produk } \\
\text { dan penyimpanan } \\
\text { barang } \\
\text { (2) Melakukan } \\
\text { berbagai } \\
\text { pemodelan } \\
\text { proses pengadaan } \\
\text { ulang dengan } \\
\text { tujuan: eliminasi } \\
\text { tingkatan fase } \\
\text { otorisasi, } \\
\text { pengaturan } \\
\text { situasi } \\
\text { khusus/pengecua } \\
\text { lian pada tahap } \\
\text { awal } \\
\text { implementasi, } \\
\text { integrasi dengan } \\
\text { pemasok, } \\
\text { petunjuk lainnya } \\
\text { mulai dari proses } \\
\text { pencarian artikel } \\
\text { pada katalog } \\
\text { sampai dengan } \\
\text { penerbitan } \\
\text { invoice }\end{array}$} \\
\hline Bayer & & & (1) & $\begin{array}{l}\text { Mekanisme } \\
\text { otorisasi yang } \\
\text { memperluas level } \\
\text { staf yang mampu } \\
\text { melakukan otorisasi } \\
\text { dengan skala } \\
\text { transaksi tertentu }\end{array}$ & (1) & $\begin{array}{l}\text { Mengindentifikasi } \\
\text { komoditas untuk } \\
\text { menentukan } \\
\text { strategi proses } \\
\text { pengadaan yang } \\
\text { akan digunakan } \\
\text { Dimensi baru } \\
\text { dengan pengadaan } \\
\text { servis dan } \\
\text { memulai } \\
\text { pembuatan } \\
\text { katalog jasa } \\
\text { pertama kali } \\
\text { dengan model } \\
\text { 'bundling' } \\
\text { Mengembangkan } \\
\text { cc- chemplorer } \\
\text { (2000) - a } \\
\text { multivendor } \\
\text { katalog dengan } \\
\text { 169.000 produk }\end{array}$ & $\begin{array}{ll}\text { (1) } & \text { Membangun } \\
\text { standar } \\
\text { direktori } \\
\text { untuk jasa } \\
\text { servis } \\
\text { pemeliharaan }\end{array}$ & \\
\hline $\begin{array}{l}\text { Cisco System, } \\
\text { Inc. }\end{array}$ & & & & & & & $\begin{array}{l}\text { Cisco memilih } \\
\text { sistem Ariba yang } \\
\text { dapat } \\
\text { diintegrasikan } \\
\text { pada Oracle dan } \\
\text { People Soft yang } \\
\text { telah digunakan } \\
\text { untuk mendukung } \\
\text { sistem operasional } \\
\text { mereka pada saat } \\
\text { itu, dimana Ariba } \\
\text { diperhitungkan } \\
\text { sebagai sistem } \\
\text { yang efisien dan } \\
\text { mudah beadaptasi } \\
\text { terhadap } \\
\text { peningkatan } \\
\text { volume transaksi } \\
\text { seiring dengan } \\
\text { pertumbuhan } \\
\text { bisnis perusahaan }\end{array}$ & \\
\hline SAP, AG & & & (1) & $\begin{array}{l}\text { Memangkas hirarki } \\
\text { otorisasi dari enam }\end{array}$ & (1) & $\begin{array}{l}\text { Mengintegrasikan } \\
\text { sistem pemasok }\end{array}$ & $\begin{array}{l}\text { Memilih sistem } \\
\text { yang memudahkan }\end{array}$ & \\
\hline
\end{tabular}




\begin{tabular}{|c|c|c|c|c|}
\hline & & $\begin{array}{l}\text { menjadi satu } \\
\text { (2) Perampingan proses } \\
\text { pengadaan }\end{array}$ & $\begin{array}{l}\text { ke sistem } e \text { - } \\
\text { procurement } \\
\text { internal } \\
\text { (2) Mengembangkan } \\
\text { e-market (emaro) } \\
\text { yang bertujuan } \\
\text { untuk } \\
\text { mengumpulkan } \\
\text { volume yang } \\
\text { besar untuk } \\
\text { melakukan } \\
\text { pengadaan } \\
\text { sekaligus dan } \\
\text { melakukan } \\
\text { standarisasi } \\
\text { dengan sistem } \\
\text { pengadaan dari } \\
\text { pemasok lainnya. }\end{array}$ & $\begin{array}{l}\text { perusahaan dalam } \\
\text { berintegrasi } \\
\text { dengan sistem } \\
\text { lainnya. Misalnya } \\
\text { dengan koneksi } \\
\text { emaro dapat } \\
\text { terhubung dengan } \\
\text { sistem pemasok } \\
\text { untuk melakukan } \\
\text { proses pemesanan } \\
\text { dan sistem } \\
\text { akuntansi. }\end{array}$ \\
\hline Xerox Ltd & & & & $\begin{array}{l}\text { Melakukan } \\
\text { evaluasi secara } \\
\text { komprehensif } \\
\text { terhadap } \\
\text { pemilihan sistem } \\
\text { e-procurement } \\
\text { yang akan } \\
\text { digunakan sebagai } \\
\text { alternatif terbaik } \\
\text { yang disesuaikan } \\
\text { dengan kekuatan } \\
\text { proses rantai } \\
\text { pasokan } \\
\text { perusahaan } \\
\end{array}$ \\
\hline $\begin{array}{l}\text { City of } \\
\text { Helsinky }\end{array}$ & $\begin{array}{l}\text { Memilih pemasok } \\
\text { berdasarkan nilai } \\
\text { yang ada } \\
\text { diperusahaan, } \\
\text { tidak semata } \\
\text { melihat harga } \\
\text { yang murah }\end{array}$ & $\begin{array}{l}\text { Membangun Financial } \\
\text { Shared Service Center } \\
\text { (SSC) dengan pembelian } \\
\text { yang tersentralisasi }\end{array}$ & $\begin{array}{l}\text { Efisiensi biaya } \\
\text { administratif dengan } \\
\text { volume pembelian } \\
\text { yang besar (dampak } \\
\text { dari sentralisasi } \\
\text { pembelian) }\end{array}$ & $\begin{array}{l}\text { Software as a } \\
\text { Service (SAAS), } \\
\text { katalog dibangun } \\
\text { (hostin) di lokasi } \\
\text { yang ditentukan IT } \\
\text { vendor tapi } \\
\text { menggunakan } \\
\text { aturan perusahaan } \\
\text { dalam melakukan } \\
\text { transaksi bersama } \\
\text { pemasok. } \\
\text { Helsinky hanya } \\
\text { membayar biaya } \\
\text { perijinan dan } \\
\text { pemeliharaan. }\end{array}$ \\
\hline
\end{tabular}

Tabel 2

Matriks Strategi Pengadaan Berdasarkan karakteristik Komoditas

\begin{tabular}{lcccc}
\hline \multicolumn{1}{c}{ Kriteria } & e-catalog & Punchout & Auction & Request for quotation \\
& & & & low \\
Pemesanan & high & medium & low & high \\
Volume per pemesanan & low & low & high & low \\
Permintaan & high & medium & low & medium \\
Supplier & low & low & high & medium \\
Tingkat Standarisasi & high & medium & high & medium \\
Kompetisi & low & low & high & \\
\hline
\end{tabular}




\section{Desain Model}

Pada tahapan ini akan dibahas pemetaan kunci keberhasilan dari contoh keberhasilan perusahaan yang menerapkan sistem e-procurement, sehingga model ini dapat menunjang keberhasilan dalam mengimplementasikan sistem e-procurement. Diharapkan kapabilitas dari sistem e-procurement dapat dimanfaatkan secara optimal sehingga perusahaan tidak hanya dapat mengalami peningkatan dalam efisiensi pada proses pengadaan produk dan biaya, juga dapat menggali nilai tambah lainnya dari kemampuan yang disediakan sistem e-procurement. Kelima tahapan di atas terangkum pada bagan di bawah ini (Gambar 2).

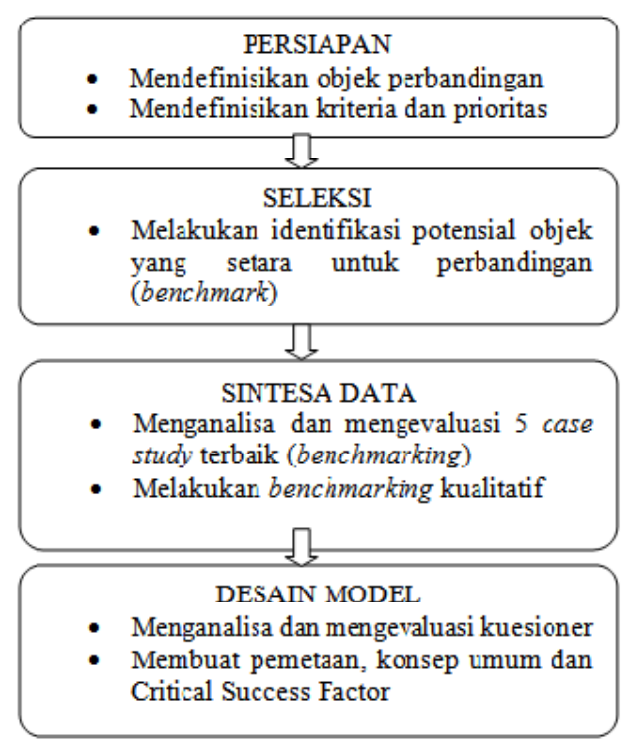

Gambar 2. Tahapan metode penelitian.

\section{HASIL DAN PEMBAHASAN}

Berikut adalah beberapa hal yang menjadi faktor penentu keberhasilan beberapa perusahaan dalam menerapkan sistem e-procurement (Tabel 3):

Tabel 3

Hasil Studi Pembandingan Faktor Keberhasilan Implementasi E-Procurement

\begin{tabular}{ll}
\hline Persiapan Project & (1) Penyelarasan proses pengadaan dalam perusahaan dengan e-procurement; \\
& (2) Persiapan yang matang dalam pembuatan catalog; \\
(3) Memperlebar jaringan pemasok yang dipreferensikan dan strategis dalam perencanaan untuk $e$ - \\
procurement
\end{tabular}


Manajemen Katalog

(1) Mengindentifikasikan strategi e-procurement yang tepat untuk setiap komoditas;

(2) Standarisasi produk, katalog dan proses - Pelaksana dari sistem e-procurement harus menyiapkan arsitektur teknis dari sistem yang meliputi aturan alur kerja yang terdapat dalam program yang mengatur tugas-tugas yang terlibat dalam proses pengadaan (Rajkumar, 2001; Hope-Ross, et al, 2000; Harapan-Ross \& Reilly, 23 Februari 2000);

(3) Membangun strategi penempatan (hosting) katalog

Penyelearasan strategi $e$ procurement dan proses bisnis

(1) Menyelaraskan strategi dan pemilihan sistem e-procurement dengan proses bisnis perusahaan dan proses pemasok. Dengan melakukan penyelarasan proses dan integrasi bersama supplier akan memberikan banyak keuntungan yang signifikan (Attaran \& Attaran, 2002; Anonymous, 2001; Rajkumar, 2001; Hope-Ross \& Reilly, February 16, 2000);

(2) Mengembangkan e-procurement berdasarkan isu yang muncul didalam proses bisnis dan melakukan proses analisis biaya-manfaat (Hope-Ross, et al, 2000.). Penentuan biaya akan terbukti menantang karena luasnya variabilitas dalam harga aplikasi e-procurement (Hope-Ross \& Reilly, 2000). Dalam mengevaluasi potensi vendor perangkat lunak e-procurement, perusahaan harus mempertimbangkan isu-isu penting berikut: fungsi perangkat lunak, arsitektur teknis, biaya, dukungan dan pelayanan, potensi kedepan dan visi perusahaaan(Hope-Ross \& Reilly, 1 Maret 2000)

(3) Integrasi sistem procurement dengan sistem operasional internal lainnya yang terkait dan eksternal (pemasok). Trend berikutnya adalah melakukan collaborative procurement, dimana kolaborasi ini ditujukan untuk meningkatkan hubungan antara pemasok dan pembeli tanpa proses manual namun dengan menggunakan teknologi internet seperti portal, dimana terdapat komunikasi 2 arah, dan first-tier supplier akan memenuhi kebutuhan dari rencana produksi dan rantai pasokan dari perusahaan dengan data yang real time (Puschmann \& Alt, 2005);

(4) Menerapkan standarisasi untuk katalog dan data interchange

Pemeliharaan Peningkatan Efisiensi Operasional
(1) Membuat pemodelan ulang proses pengadaan untuk meningkatkan efisiensi;

(2) Terus menerus melakukan monitoring proses internal, mencari peluang untuk meningkatkan efisiensi pada proses pengadaan didalam perusahaan;

(3) Menggunakan alat untuk melakukan pengukuran efisiensi, misalnya balanced scorecard;

(4) Pada perusahaan perlu dilakukan pengukuran terhadap produktifitas dan efisiensi yang dihasilkan dengan pemanfaatan sistem e-procurement, sehingga dapat memonitor bagian-bagian yang perlu ditingkatkan dari sebelumnya;

\section{PENUTUP}

Di sisi internal, implementasi sistem e-procurement yang berhasil telah memberikan banyak visibilitas dan transparansi transaksi pengeluaran perusahaan baik secara individual maupun skala unit dalam perusahaan, yang mendukung peningkatan efisiensi terhadap proses dan biaya. Dengan kemampuan ini perusahaan dapat melakukan jejak audit dalam sistem, memahami pola pengeluran yang terjadi dan menyediakan informasi yang mendukung manajemen dalam pengambilan keputusan yang lebih efektif, meningkatkan kinerja pemasok, mengoptimalkan anggaran dan perencanaan.

Namun hasil studi perbandingan dari implementasi sistem e-procurement pada beberapa perusahaan menunjukkan bahwa implementasi e-procurement berbicara kuat tentang isu non-teknis yang terkait dengan aspek organisasi yang melibatkan perubahan pada proses pengadaaan dan organisasinya. Desentralisasi fungsi pada bagian pengadaan dalam perusahaan besar menjadi salah satu hambatan dalam membentuk sinergi secara volume pada level korporat, sehingga perlu dikembangkan fungsi pengadaan yang tersentralisasi untuk mendukung efisiensi biaya operasional dan administrasi. Dengan dukungan organisasi, proses dan arsitektur yang memadai untuk implememtasi e-procurement memungkin perusahaan dapat berpindah dari penanganan operasional transaksi demi transaksi pengadaan ke posisi yang strategis dalam melakukan manajemen pemasok untuk memaksimalkan nilai tambah bagi perusahaan, dan juga dapat melakukan integrasi yang tidak hanya berfokus pada lingkup internal tapi juga dapat menyentuh tingkat global. 


\section{DAFTAR PUSTAKA}

Angeles, Rebecca., Nath, Ravinder. (2005). Critical Success Factors for Implementation of Busines to Business Electronic Procurement. 5 (1).

Attaran, M., \& Attaran, S. (2002). Catch the Wave of E-procurement. Industrial Management,11(3).

Boutellier, R., Baumbach, M. and Bodmer, C. (1999). Successful Practices in After-Sales Management. IO Management, 68 (1), 23-7.

Camp, R. (1989). Benchmarking: The Search for Industry Best Practices that Lead to Superior Performance. Milwaukee: ASQC Quality Press.

Dooley, Ken., Sharon. (2006). Factors Influencing E-procurement Usage. Journal of Public Procurement, 6 (1\&3), 28-45.

Hope-Ross, D. (2001). E-procurement Odyssey: 2002 and Beyond. Retrieved February 17, 2003, from http://www.gartner.com/DisplayDocument?id=350276

Hope-Ross, D., \& Reilly, B. (2000, February 23). CEO and CIO Update: E-procurement Yields Benefits But Takes Planning, Time, Work. (Gartner Advisory). Retrieved January 19, 2003, from http://www.gartnergroup.com..

Hope-Ross, D., \& Reilly, B. (2000, March 1). CIO Update: Criteria for Selecting the Right E Procurement Vendors and Software. (Gartner Advisory). Retrieved January 18, 2003, from http://www.gartnergroup.com

Hope-Ross, D., Luebbers, J., Purch ase, E., \& Reilly, B. (2000, February 9). E-procurement: A Blueprint for Revolution or Hype? (Strategy \& Tactics/Trends \& Direction). Retrieved January 22, 2003, from http://www.gartnergroup.com.

Pearcy, Dawn H.,Parker, Delvon B.,Giunipero, Larry C.(2008). Using Electronic Procurement to Facilitate Supply Chain Integration: An Exploratory Study of US-Based Firms. American Journal of Business, 23 (1), 23.

Puschmann, Thomas., Alt, Rainer. (2005). Successful Use Of E-Procurement in Supply Chains. Supply Chain Management: An International Journal, 10 (2), 122 - 133.

Rajkumar, T. M. (2001). E-procurement: Business and Technical Issues. Information Systems Management, 18 (4), 52-61.

Smeltzer, L. R. (2001). How to Build an E-Procurement Strategy. Supply Chain Management Review, 5 (3), $76-83$. 